\title{
Clonal Composition of Benign and Malignant Human Thyroid Tumors
}

\author{
Hiroyuki Namba, Keiichi Matsuo, and James A. Fagin \\ Department of Medicine, Cedars-Sinai Medical Center, University of California at Los Angeles School of Medicine, \\ Los Angeles, California 90048
}

\begin{abstract}
We determined clonality of thyroid tumors from female patients who had restriction fragment length polymorphisms (RFLP) in the X chromosome genes hypoxanthine phosphoribosyltransferase (HPRT) or phosphoglycerate kinase (PGK). We screened normal thyroid tissue from 59 female patients; of the informative cases 14 were heterozygous for a Bgl I site on PGK and 4 were heterozygous for a Bam HI site on HPRT. In monoclonal tumors, one of the polymorphic alleles was selectively digested after additional digestion with Hpa II, a methylation sensitive enzyme, whereas in polyclonal tissue both were decreased to a similar extent. Normal thyroid tissue from all patients showed a polyclonal pattern. Of the 18 tumors studied, 12 were solitary thyroid nodules, and 6 were obtained from multinodular goiters (MNG). The following were monoclonal: 6/6 follicular adenomas, 2/2 follicular carcinomas, and 1/1 anaplastic carcinoma. Two of the three papillary carcinomas showed intermediate patterns, possibly due to contaminating effects of stromal tissue present in most of these neoplasms. Of the six nodules from MNG, four were polyclonal. The two largest gave a distinct monoclonal pattern. Most solitary thyroid tumors are monoclonal, supporting a somatic cell mutation model of thyroid neoplasm formation. Nodules from MNG are largely hyperplastic, although monoclonal neoplasms do occasionally arise within these glands. The specific somatic mutations leading to clonal expansion and determination of tumor phenotype are presently unknown. (J. Clin. Invest. 1990. 86:120-125.) Key words: follicular neoplasm • papillary carcinoma - multinodular goiter - $X$ chromosome inactivation phosphoglycerate kinase $\bullet$ hypoxanthine phosphoribosyltransferase
\end{abstract}

Introduction

In the United States, clinically apparent thyroid nodules are present in $4-7 \%$ of the adult population (1). There is still no consensus as to the best management of these common endocrine tumors. Preoperative diagnostic techniques offer low specificity, which results in a substantial number of unnecessary operations, and in some patients who are inappropriately left untreated. Even after careful histopathological examination of surgical specimens, it can occasionally be problematic to decide whether a particular thyroid nodule is hyperplastic or

Address reprint requests to Dr. Fagin, Cedars-Sinai Medical Center, Division of Endocrinology, Becker Building 131, 8700 Beverly Blvd., Los Angeles, CA 90048.

Received for publication 9 October 1989 and in revised form 6 February 1990.

J. Clin. Invest.

(c) The American Society for Clinical Investigation, Inc. 0021-9738/90/07/120/06 \$2.00

Volume 86, July 1990, 120-125 neoplastic, and in the case of neoplasms, to differentiate a follicular adenoma from a carcinoma. There have been several studies documenting discrepancies between observers in the pathological diagnosis of thyroid tumors, which are reported to occur in up to $24 \%$ of cases $(2,3)$. These difficulties stem from major gaps in our knowledge of the biology of thyroid neoplasms.

Understanding the origin of neoplasia may be advanced by studying the clonal composition of tumor cell populations. Since thyroid neoplasms are a heterogeneous group of disorders that differ in their histopathological and clinical characteristics, determining their clonal composition will provide valuable information for future studies into their pathogenesis. If tumors arise from a single cell, a somatic cell mutation model of thyroid neoplasm formation will be likely (4). Conversely, the existence of polyclonal tumors will suggest that extrinsic growth-promoting factors (i.e., TSH or other growth factors) may play a determining role in tumor formation.

Determination of clonality can be achieved by $\mathrm{X}$ chromosome inactivation analysis. This methodology takes advantage of the fact that, according to the Lyon hypothesis (5), one of the two X chromosomes in all female somatic cells is functionally inactivated early in mammalian embryogenesis. X-inactivation is a random process in which either the maternally or paternally derived $\mathrm{X}$ can be inactivated; once established, however, $\mathrm{X}$-inactivation is fixed for a given cell and its progeny (6). Normal polyclonal female tissue is a mosaic consisting of a roughly equal mixture of two types of cells, some of which contain an active maternal $\mathrm{X}$ chromosome, while others possess active paternal $\mathrm{X}$ chromosomes. In the past, clonal analyses have been performed by examining the protein polymorphism exhibited by glucose 6 phosphate dehydrogenase $(\mathrm{G} 6 \mathrm{PD})^{1}(7,8)$, a protein coded for in the $\mathrm{X}$ chromosome. This strategy has the drawback that G6PD polymorphism is only observed in a small proportion of black females (9). Furthermore, false results can be obtained if the tumor cell type expresses the gene at a different rate than the surrounding mesenchymal cells. Since somatic cells contain the same amounts of DNA, these problems are avoided by using markers present in $\mathrm{X}$ chromosome genes. Recently, restriction fragment length polymorphisms (RFLPs) have been identified that can distinguish the maternal and paternal copies of certain $\mathrm{X}$ chromosome genes from one another (10). Furthermore, there is evidence that changes in the expression of many genes, including those in the $\mathrm{X}$ chromosome, are accompanied by changes in the methylation of cytosine residues (11). Methylation differences can be identified by certain restriction endonucleases that will differentially digest DNA according to whether or not

1. Abbreviations used in this paper: ACR, allelic cleavage ratio; G6PD, glucose 6-phosphate dehydrogenase; HPRT, hypoxanthine phosphoribosyltransferase; MNG, multinodular goiter; PGK, phosphoglycerate kinase; RFLP, restriction fragment length polymorphism. 
their recognition sequences contain methylated cytosine residues.

Combined DNA digestion with a methylation-specific enzyme and the restriction enzyme giving rise to an RFLP determines whether a population of tumor cells or tissue is monoclonal or polyclonal $(12,13)$. With this approach, using RFLPs in the $\mathrm{X}$ chromosome genes hypoxanthine phosphoribosyltransferase (HPRT) and phosphoglycerate kinase (PGK), the clonal origin of a variety of human benign and malignant neoplasms has been determined (14). Arnold et al. have utilized this technique to undertake the clonal analysis of human parathyroid adenomas (15). They found it useful in distinguishing parathyroid adenomas (which showed a monoclonal pattern) from parathyroid hyperplasia (polyclonal pattern).

As will be detailed in this report, we found using HPRT and PGK gene polymorphisms as markers that most solitary benign and malignant thyroid tumors do indeed appear to be monoclonal. Although most nodules from multinodular goiters were polyclonal, large tumors arising within these glands occasionally showed monoclonal patterns, suggesting that somatic cell transformation can give rise to true neoplasms in these predominantly hyperplastic goiters.

\section{Methods}

Thyroid tumor collection. Thyroid nodules from female patients were obtained at surgery and immediately frozen in liquid nitrogen. Attending pathologists were requested to provide tumor samples from within the capsule to prevent contamination with normal thyroid tissue. Whenever possible, normal thyroid tissue from the same individual was collected separately. In patients with multinodular goiters (MNG), samples were taken from the largest available tumor, and lymphocyte preparations from peripheral blood were used as a source of normal polyclonal tissue.

Rationale for $X$ chromosome inactivation analysis (12-14). To determine clonality of tumors by this strategy requires two conditions: $(a)$ a method of distinguishing the two $\mathrm{X}$ chromosome alleles from each other, and b) the ability to tell which $X$ chromosome(s) are active in a given cell population. To distinguish the paternal from the maternal alleles, we identified female patients with heterozygous polymorphisms in either the X chromosome gene PGK and/or HPRT. In the PGK gene there is a polymorphic Bgl I site. 33\% of females are heterozygous for this site. After Eco RI-Bgl II digestion, subsequent digestion with Bgl I will reveal bands of 1.7 and $1.3 \mathrm{~kb}$ in heterozygous women. The HPRT gene contains a polymorphic Bam HI site present in $16 \%$ of $\mathrm{X}$ chromosomes. DNA from females heterozygous for this Bam $\mathrm{H} 1$ site will show bands of 24 and $12 \mathrm{~kb}$ after Bam HI digestion, or of 18 and $12 \mathrm{~kb}$ after Bam HI-Pvu II digestion.

These polymorphisms are in the vicinity of methylation sites, which differ in their methylation status according to whether the gene is active or inactive. We determined the methylation status of each of the polymorphic alleles by additional digestion with the methylation sensitive enzyme Hpa II. The HPRT gene has two Hpa II sites that are methylated in all inactive $\mathrm{X}$ chromosomes, whereas one or the other of these is unmethylated in active $X$ chromosomes. Hpa II digestion of Bam HI/Pvu II digested DNA of a heterozygous female will be expected to show reduced intensity of both the 18 - and the $12-\mathrm{kb}$ fragments if the tumor tissue is polyclonal. If the tumor is monoclonal, the 18- and 12-kb alleles will not be digested equivalently by Hpa II, and one of them, the inactive allele, will disappear completely. Exceptionally, Hpa II sites 2-9 may be methylated in the inactive allele (type II alleles), and therefore even monoclonal neoplasms will show resistance to Hpa II digestion of both the 18- and 12-kb fragments using the HPRT-800 probe (14). We encountered two such examples in our series, which were considered noninformative. In the PGK studies,
Hpa II digestion of Eco RI-Bgl II/Bgl I-digested tumor DNA probed with the PGK clone will be expected to show $60-75 \%$ reduction in the intensity of both the 1.7 - and $1.3-\mathrm{kb}$ alleles if the tumor is polyclonal. If the tumor is monoclonal, one allele will be selectively decreased by Hpa II digestion. Exceptionally, monoclonal tumors may have both alleles completely digested away with Hpa II (14). We found one such case, which was considered noninformative. The PGK probe has been reported to cross-hybridize to a PGK-related Eco RI-Bgl II fragment of $\sim 1.7 \mathrm{~kb}(14)$. With the stringency conditions used in our study we did not encounter this problem, as evidenced by consistently obtaining complete Hpa II cleavage of control male DNA containing a $1.7-\mathrm{kb}$ PGK allele.

DNA extraction. DNA was extracted from tissues and lymphocytes by ultracentrifugation through a cesium chloride gradient (16). Briefly, thyroid tissue was ground under liquid $\mathrm{N}_{2}$ using mortar and pestle. The DNA layer was recovered after ultracentrifugation through a 2.4-M and $5.7-\mathrm{M} \mathrm{CsCl}$ cushion and precipitated in $2.5 \mathrm{vol}$ of ethanol. The DNA was recovered by spooling, rinsed in $10 \mathrm{ml}$ of $80 \%$ ethanol, and digested at $37^{\circ} \mathrm{C}$ for $48 \mathrm{~h}$ with $1 \mu \mathrm{g} / \mathrm{ml}$ proteinase $\mathrm{K}$ in a buffer containing $150 \mathrm{mM} \mathrm{NaCl}, 10 \mathrm{mM}$ Tris, $\mathrm{pH} 7.5,10 \mathrm{mM}$ EDTA and $0.4 \%$ SDS. The mixture was then phenol-chloroform extracted. Sodium acetate (final concentration $0.3 \mathrm{M}$ ) was added to the aqueous layer, which was then ethanol-precipitated. After rinsing the pellet twice with $70 \%$ ethanol, the DNA was pelleted, air dried, and resuspended in $\mathrm{H}_{2} \mathrm{O}$. After quantification by absorption at $260 \mathrm{nM}$, extracts were stored at $4^{\circ} \mathrm{C}$ until assayed.

DNA digestion and gel electrophoresis. All restriction endonucleases were purchased from BRL (Bethesda, MD) and used at 3-5 U/ $\mu \mathrm{g}$ DNA. For the HPRT study, $24 \mu \mathrm{g}$ DNA was digested with Bam HI and Pvu II in a buffer consisting of $200 \mu \mathrm{g} / \mathrm{ml} \mathrm{BSA}, 100 \mathrm{mM} \mathrm{NaCl}, 10 \mathrm{mM}$ $\mathrm{MgCl}_{2}, 10 \mathrm{mM}$ Tris, pH 7 at $37^{\circ} \mathrm{C}$ for $3 \mathrm{~h}$. After digestion, the DNA was ethanol precipitated, dried in vacuo and dissolved in $0.12 \mathrm{ml}$ of 3 $\mathrm{mM}$ Tris, $0.2 \mathrm{mM}$ EDTA, pH 7.5. Completeness of digestion was assessed by ethidium bromide staining of a $1 \%$ agarose gel after electrophoresis of $0.02 \mathrm{ml}$ of the digestion product. The remaining volume was then divided into two aliquots of $0.05 \mathrm{ml}$ each. One aliquot was digested with Hpa II using the manufacturers recommended buffer and the other left undigested. For the PGK study, $24 \mu \mathrm{g}$ DNA was digested with Eco $\mathrm{RI}$ and $\mathrm{Bgl} \mathrm{I}$ for $3 \mathrm{~h}$ at $37^{\circ} \mathrm{C}$ in a buffer consisting of $200 \mu \mathrm{g} / \mathrm{ml} \mathrm{BSA}, 50 \mathrm{mM}$ Tris $\mathrm{HCl}, 10 \mathrm{mM} \mathrm{MgCl}_{2}, 50 \mathrm{mM} \mathrm{NaCl}$, pH 8 . The reaction was then heated to $70^{\circ} \mathrm{C}$ for $15 \mathrm{~min}$ to inactivate the enzymes. After adjusting the buffer concentrations, the DNA was digested with Bgl II for $3 \mathrm{~h}$ at $37^{\circ} \mathrm{C}$. Each reaction was then ethanol precipitated, dissolved in $0.1 \mathrm{ml} \mathrm{H}_{2} \mathrm{O}$ and divided into two aliquots as described above. One aliquot was digested with Hpa II, and the other was left undigested. Electrophoresis was performed in $1 \%$ agarose gels, and the DNA was transferred to nylon membranes by capillarity as previously described (17).

Hybridization. After DNA transfer, filters were prehybridized for $12 \mathrm{~h}$ at $42^{\circ} \mathrm{C}$, and then hybridized in $10 \mathrm{ml}$ hybridization buffer containing $50 \%$ formamide, $5 \times$ SSPE $(1 \times \mathrm{SSPE}=43.8 \mathrm{~g}$ /liter NaCl, 6.9 $\mathrm{g} /$ liter $\mathrm{NaH}_{2} \mathrm{PO}_{4}-\mathrm{H}_{2} \mathrm{O}$, and $1.85 \mathrm{~g} /$ liter EDTA), $5 \times$ Denhardt's solution $(1 \mathrm{~g} /$ /iter polyvinyl-pyrrolidone, $1 \mathrm{~g} /$ /iter BSA and $1 \mathrm{~g} /$ /iter Ficoll 400), $0.1 \%$ SDS and $200 \mathrm{ng} / \mathrm{ml}$ salmon sperm DNA for $48 \mathrm{~h}$ at $42^{\circ} \mathrm{C}$ with ${ }^{32} \mathrm{P}$-labeled DNA probes. After hybridization the filters were washed twice in $2 \times \operatorname{SSC}(1 \times \mathrm{SSC}=0.15 \mathrm{M} \mathrm{NaCl}$ and $0.015 \mathrm{M}$ sodium citrate), $0.1 \% \mathrm{SDS}$ at room temperature, and then at $55^{\circ} \mathrm{C}, 58^{\circ} \mathrm{C}$, and $60^{\circ} \mathrm{C}$ in $0.1 \times \mathrm{SSC}, 0.1 \%$ SDS for $30 \mathrm{~min}$ each. Filters were then exposed for autoradiography to Kodak XAR-5 film for 12-72 $\mathrm{h}$ at $70^{\circ} \mathrm{C}$.

Probes. For the HPRT gene we used an 800 bp Hpa II/Pst I subfragment of clone BP 1.6 from the $5^{\prime}$ region of the gene (provided by A. Craig Chinault, Baylor College of Medicine, Houston, TX) (13). For the PGK gene, we used an $800 \mathrm{bp} \mathrm{Eco} \mathrm{RI/Bam} \mathrm{HI} \mathrm{fragment} \mathrm{of} \mathrm{the} 5^{\prime}$ end of the gene from clone pSPT/PGK (provided by A. Riggs, City of Hope, Duarte, CA). Probes were labeled with [ $\left.{ }^{32} \mathrm{P}\right] \mathrm{dCTP}$ using the random primer technique (18) following the manufacturer's protocol (Boehringer Mannheim, Indianapolis, IN). 
Table I. Histological Diagnoses of Thyroid Neoplasms Undergoing Clonal Analysis

\begin{tabular}{ll} 
Benign & \\
Follicular adenomas & 6 \\
$\quad$ Tumors from nodular goiters & 6 \\
Malignant & 3 \\
Papillary carcinomas & 2 \\
Follicular carcinomas & 1 \\
Anaplastic carcinoma & \\
\hline
\end{tabular}

Allelic cleavage ratio $(A C R)(15)$. To quantify the relative selectivity of Hpall cleavage of the polymorphic alleles, we compared the Hpa II-induced change in densitometry intensity of both bands and calculated their ratio according to the following formula: Upper band (-Hpa II)/upper band (+Hpa II) divided by lower band (-Hpa II)/ lower band (+Hpa II). Polyclonal tissues would be expected to have ACR of $\sim 1$

\section{Results}

We screened normal tissue DNA from 59 female patients undergoing thyroid surgery for the presence of heterozygous polymorphisms in the HPRT and/or the PGK genes. Individuals heterozygous for the respective polymorphic sites revealed the presence of two bands upon digestion with the appropriate restriction enzymes. Normal thyroid tissue from all informative cases showed a polyclonal pattern upon further digestion with Hpa II, and their tumors could thus be subjected to clonal analysis. 18 of the 59 patients had heterozygous RFLPs and the tumor DNA was informative: 14 for PGK, and 4 for HPRT. The histological diagnoses of the thyroid tumors from the 18 patients is shown in Table $I$.

Most of the tumors presenting clinically as solitary nodules showed the selective disappearance of one of the polymorphic alleles after digestion with the methylation-sensitive enzyme Hpa II. This indicates that all cells in those tumors contained the same allele activated, and therefore that they arose from a single precursor cell. Examples of such monoclonal neoplasms are seen in Fig. 1. Altogether, 6/6 follicular adenomas (ACR: $8.1,64,13.4,13.8,16.6$ and 14), 2/2 follicular carcinomas (ACR: 16.5 and 13.9), and an anaplastic carcinoma (ACR 3.3) had monoclonal patterns. Data for papillary carcinomas are shown in Fig. 2. The patterns observed showed a spectrum ranging from clearly monoclonal $(10, A C R 4.5)$, intermediate (11, ACR: 3.1) and polyclonal (12, ACR 1.7). As is the case for most papillary carcinomas, these tumors had a substantial stromal component within the pathological sample.

6 of the 14 female patients with MNG we screened had heterozygous polymorphisms in either the HPRT or the PGK genes, and their thyroid tumors could be subjected to clonal analysis. In all cases, samples were taken from within the largest nodule in the pathological specimen. The nodules from four patients gave polyclonal patterns (both alleles were equally decreased after digestion with the methylation sensitive enzyme Hpa II), as shown in the top row of Fig. 3 (ACR: $1.3,1.0,0.86$, and 1.14 , respectively). Two tumors (bottom row), however, gave distinct monoclonal patterns (ACR: 22.8 and 4.5), indicating that the clonal origin of nodules within multinodular goiters is heterogeneous. It is noteworthy that

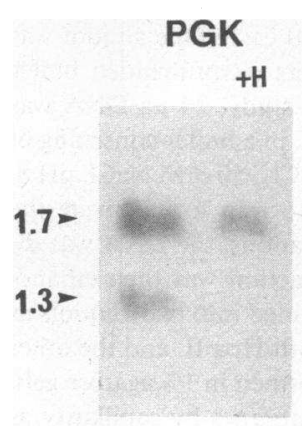

1

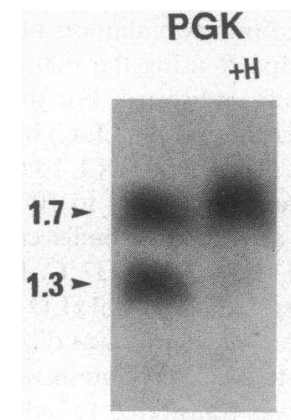

2

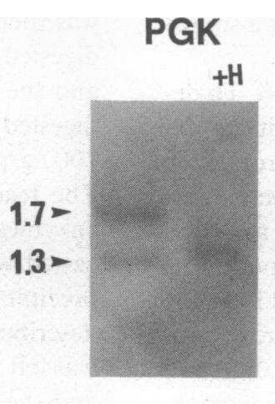

3

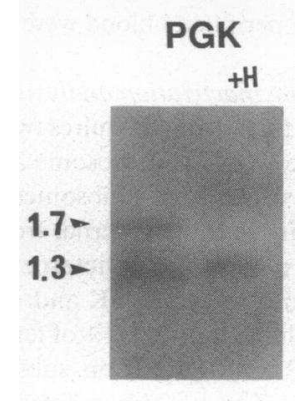

4

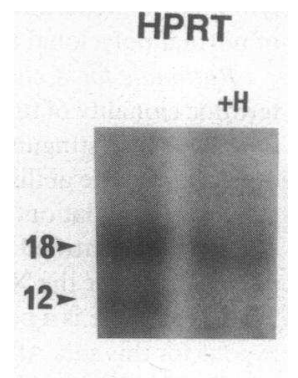

5
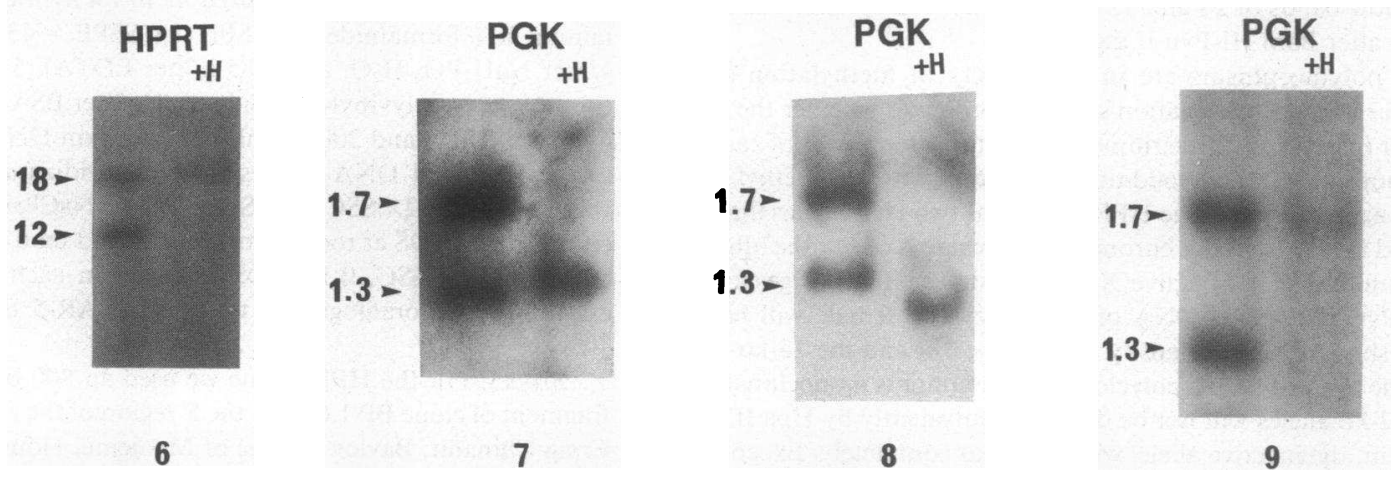

Figure 1. Examples of monoclonal thyroid neoplasms demonstrated by $X$ chromosome inactivation analysis with the PGK or the HPRT probes. Thyroid tumor DNA was digested with either Bam HI-Pvu II (HPRT) or Eco RI-Bgl II-Bgl I (PGK) to reveal the respective polymorphisms. Lanes marked $+\mathrm{H}$ indicate additional digestion with HpalI. (1-6) Follicular adenomas. (7, 8) Follicular carcinomas. (9) Anaplastic carcinoma. Arrows indicate size of restriction fragments. 


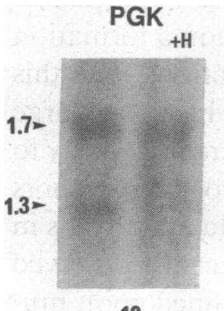

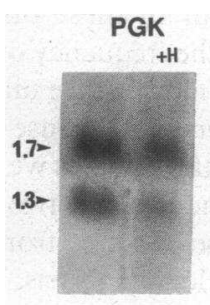

11

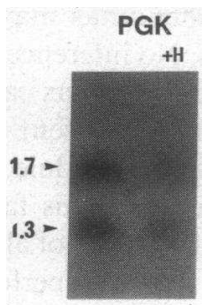

Figure 2. Examples of clonal patterns in three papillary carcinomas heterozygous for the Bgl I site in the PGK gene. $+\mathrm{H}$ : additional digestion with HpalI. Arrows indicate size of restriction fragments.

the two monoclonal MNG tumors were the largest such masses examined, and were histologically distinguishable by a monomorphous follicular pattern (data not shown).

\section{Discussion}

Somatic mutation theories of carcinogenesis, regardless of the number of steps required to induce the malignant state, predict that the resulting tumors will be monoclonal in origin, since it is unlikely that an identical sequence of mutations will occur independently in two neighboring cells. A detailed understanding of the clonal nature of the various forms of thyroid nodular disease is particularly relevant, since many thyroid

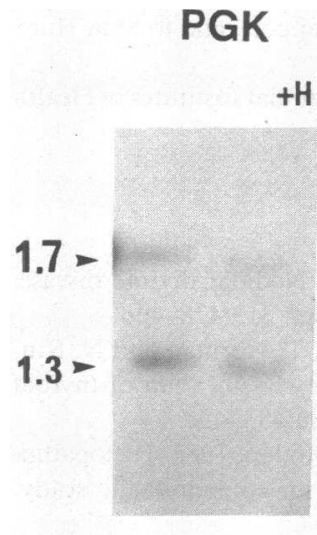

13

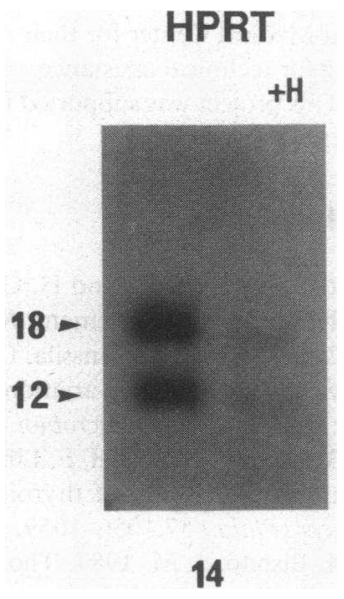

PGK

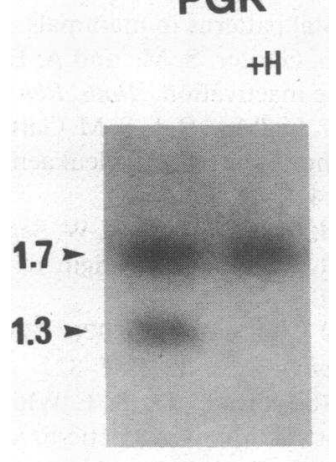

17 nodules are believed to arise (or progress) under the influence of pituitary thyroid-stimulating hormone (TSH), TSH receptor-binding immunoglobulins, or other goitrogens. Furthermore, hyperplastic thyroid nodules and thyroid adenomas are often not easily distinguished by histopathology $(2,3)$.

Thomas et al. studied the clonal origin of thyroid tumors in female mice heterozygous for a deficiency of the X chromosome-linked enzyme G6PD (19). After inducing thyroid tumors with a variety of goitrogens, they observed that lesions identified histologically as adenomas (encapsulated, monomorphous and hypercellular) were consistently monoclonal by enzyme histochemistry. Nodules, defined as circumscribed tumors with prominent stroma and areas of normal follicular architecture, were largely polyclonal.

14 years ago, Fialkow et al. (7-9) used protein electrophoresis to differentiate the A or B isozymes of G6PD in heterozygous women in order to perform clonality studies of human tumors. Among them, he studied four follicular adenomas and five thyroid carcinomas, and found them all to be monoclonal (20). Arnold et al. established the clonal characteristics of human parathyroid adenomas using $\mathrm{X}$-chromosome gene RFLPs, which they found to be largely monoclonal (15). In this paper we have validated this latter strategy to study the clonal composition of benign and malignant thyroid neoplasms. As expected, normal thyroid tissue invariably showed a polyclonal pattern, indicating that the $\mathrm{X}$-inactivation process occurs at a point in thyroid ontogeny when the gland is already multicellular, and that normal follicular cells consist of a rela-

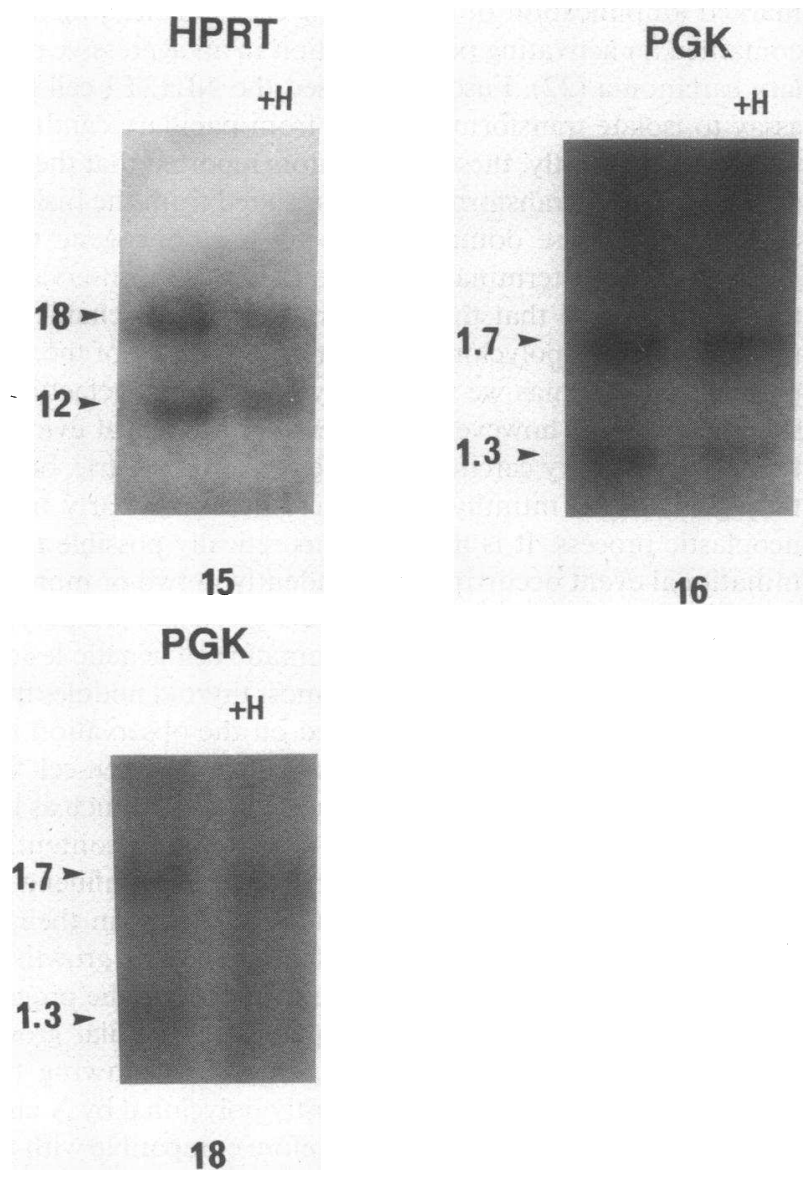

Figure 3. Clonal analysis of thyroid nodules derived from six female patients with MNG. Methods were as in legend to Fig. 1. 
tively even population of thyrocytes with active maternal and paternal X chromosome alleles. All the solitary follicular nodules we examined (six adenomas and three carcinomas) gave clear cut monoclonal patterns. We also studied three papillary carcinomas, two of which unexpectedly showed polyclonal patterns.

Several potential caveats must be discussed in the interpretation of these data. In particular, possible causes of inappropriate assignment of clonality must be considered. Firstly, improperly dissected tumor tissue may contain substantial amounts of stromal cells. As the "contaminating" nontumoral tissue will be polyclonal, the RFLP-methylation pattern will be shifted towards that observed in the patient's normal polyclonal tissues. To minimize this problem, extreme care was taken to obtain tissue from within the capsule of the nodules. In the case of the papillary carcinomas, however, a substantial amount of stromal tissue was interspersed with the neoplastic cells, which complicates the interpretation of the clonal analysis. It is also possible that some neoplasms could have unusual methylation patterns of any of the two genes, as has been reported for neuroblastomas (14). Vogelstein et al. did not encounter this phenomenon in a large variety of neoplasms (14). Other factors, such as aging, have been reported to be associated with reactivation of some inactive $\mathrm{X}$ chromosome alleles, and could conceivably lead to false polyclonal patterns. However, reactivation of the HPRT locus with aging does not appear to occur to any significant extent (21).

In all likelihood, papillary carcinomas arise due to somatic cell mutations. We have recently reported the presence of a marked amplification of a truncated H-ras allele, which also contained an activating point mutation in an aggressive papillary carcinoma (22). Fusco et al. used the NIH3T3 cell focus assay to isolate transforming DNA from papillary carcinoma tissue (23). Recently, these investigators reported that the papillary carcinoma transforming gene resulted from the fusion of the tyrosine kinase domain of the ret protooncogene to an unknown amino-terminal sequence (24). These observations therefore indicate that these tumors have clonal characteristics, and that the polyclonal pattern found in two of the three papillary carcinomas we tested may have been artefactual. It should be noted, however, that there is histological evidence that some papillary carcinomas are either multicentric, or that they give rise to intrathyroidal micrometastasis early in the neoplastic process. It is therefore theoretically possible that a mutational event occurring independently in two or more different sites within the thyroid may have given rise to a polyclonal neoplasm sharing an identical somatic cell genetic lesion.

Studer et al. have suggested that most thyroid nodules from nodular goiters are polyclonal, based on the observation that within thyroid tissues there is considerable between-cell and between-follicle variability in functional processes such as thyroglobulin synthesis, iodination and peroxidase content, as well as in growth potential (25-29). Under the influence of goitrogenic stimuli, follicular cells tend to maintain their inherent phenotypic characteristics, including their growth responsiveness, which appears to be transmitted to the progeny of the individual cells (26), and explains the nodular growth pattern observed in these glands. Our data showing that tumors from nodular goiters are mostly polyclonal by $\mathrm{X}$ chromosome inactivation analysis is therefore compatible with this model. Two of the six tumors obtained from nodular goiters, however, had distinct monoclonal patterns, indicating that true adenomas may occur in these otherwise hyperplastic glands. No inferences on the frequency of adenoma formation in nodular goiters can be made, since many patients with this condition are sent to surgery because they harbor a large "dominant" nodule, and the samples we gathered are likely to be biased by this fact. Indeed, the two monoclonal tumors were the largest of all those obtained from nodular thyroids in which we could perform clonal analysis. We recently observed that 4 of 19 tumors from nodular goiters contained point mutations of ras oncogenes (29). Interestingly, none of the polyclonal nodules had ras mutations, whereas one of the two monoclonal tumors had a point mutation in codon 12 of H-ras.

We have therefore demonstrated that most solitary nodules occurring in otherwise normal thyroid glands are monoclonal neoplasms. Conversely, tumors from nodular thyroid tissue are largely polyclonal, and are probably hyperplastic responses to goitrogenic stimuli. Within the hyperplastic glands, true adenomas may occasionally arise through one or more somatic cell mutations, which may confer these neoplasms with a growth advantage. Defining the sequence of somatic cell mutations which determine the various thyroid tumor phenotypes is of critical importance to understand the biology of these frequent neoplasms.

\section{Acknowledgments}

We are particularly indebted to Dr. Alfred Katz for his generous cooperation in providing us with thyroid tissue specimens. We are also grateful to the members of the Department of Pathology at CedarsSinai Medical Center for their continuous support, and to Shih-Huey Tang for technical assistance.

This project was supported in part by National Institutes of Health grant CA-50706.

\section{References}

1. Rojeski, M. T., and H. Gharib. 1985. Nodular thyroid disease. Evaluation and management. $N$. Engl. J. Med. 313:428-436.

2. Saxen, E., K. Franssila, O. Bjarnason, T. Norman and N. Ringertz. 1978. Observer variation of histologic classification of thyroid cancer. Acta Pathol. Microbiol. Scand. (A). 86:483-486.

3. Ron, E., B. Griffel, E. Liban, and B. Modan. 1986. Histopathologic reproducibility of thyroid disease in an epidemiologic study. Cancer (Phila.) 57:1056-1059.

4. Bishop, J. M. 1987. The molecular genetics of cancer. Science (Wash. DC). 235:305-311.

5. Lyon, M. F. 1977. X-chromosome inactivation and developmental patterns in mammals. Biol. Rev. Camb. Phylos. Soc. 47:1-35.

6. Gartler, S. M., and A. D. Riggs. 1983. Mammalian X-chromosome inactivation. Annu. Rev. Genet. 17:155-190.

7. Fialkow, P. J., S. M. Gartler, and A. Yoshida. 1967. Clonal origin of chronic myelocytic leukaemia in man. Proc. Natl. Acad. Sci. USA. 58:1468-1471.

8. Fialkow, P. J., R. W. Sagebiel, S. M. Gartler, and D. L. Rimoin. 1971. Multiple cell origin of hereditary neurofibromas. N. Engl. J. Med. 284:298-300.

9. Fialkow, P. J. 1976. Clonal origin of human tumors. Biochem. Biophys. Acta. 458:283-321.

10. Botstein, D., R. L. White, M. Stolnick, and R. W. Davis. 1980. Construction of a genetic linkage map in man using restriction fragment length polymorphisms. Am. J. Hum. Genet. 32:314-331.

11. Cantoni, G. L., and A. Razin. 1985. Chemistry, biochemistry and biology of DNA methylation. Alan R. Liss, New York.

12. Fearon, E. R., S. R. Hamilton, and B. Vogelstein. 1987. Clonal 
analysis of human colorectal tumors. Science (Wash. DC). 238:193197.

13. Vogelstein, B., E. R. Fearon, S. R. Hamilton, and A. P. Feinberg. 1985. Use of restriction fragment length polymorphisms to determine the clonal origin of human tumors. Science (Wash. DC). 227:642-645.

14. Vogelstein, B., E. R. Fearon, S. R. Hamilton, A. C. Preisinger, H. F. Willard, A. M. Michelson, A. D. Diggs, and S. H. Orkin. 1987. Clonal analysis using recombinant DNA probes from the X-chromosome. Cancer Res. 47:4806-4813.

15. Arnold, A., C. E. Staunton, H. G. Kim, R. D. Gaz, and H. M. Kronenberg. 1988. Monoclonality and abnormal parathyroid hormone genes in parathyroid adenomas. N. Engl. J. Med. 318:658-662.

16. Davis, L. G., M. D. Dibner, and J. F. Battey. 1986. Basic Methods in Molecular Biology. Elsevier, New York. pp 133-135.

17. Southern, E. M. 1975. Detection of specific sequences among DNA fragments separated by gel electrophoresis. J. Mol. Biol. 98:503-517.

18. Feinberg, A. P., and B. A. Vogelstein. 1983. A technique for radiolabelling DNA restriction endonuclease fragments to high specific activity. Anal. Biochem. 132:6-13.

19. Thomas, D. A., D. Williams, and E. D. Williams. 1989. The clonal origin of thyroid nodules and adenomas. Am. J. Pathol. 134:141-147.

20. Fialkow, P. J. 1974. The origin and development of human tumors studied with cell markers. N. Engl. J. Med. 291:26-35.

21. Migeon, B. R., J. Axelman, and A. H. Beggs. 1988. Effect of ageing on reactivation of the human X-linked HPRT locus. Nature (Lond.). 335:93-96.

22. Namba, H., R. A. Gutman, K. Matsuo, A. Alvarez, and J. A.
Fagin. 1990. H-ras protooncogene mutations in human thyroid neoplasms. J. Clin. Endocrinol. Metab. In press.

23. Fusco, A., M. Grieco, M. Santoro, M. T. Berlingieri, S. Pilotti, M. A. Pierotti, G. Della Porta, and G. Vecchio. 1987. A new oncogene in human thyroid papillary carcinomas and their lymph-nodal metastases. Nature (Lond.). 328:170-172.

24. Grieco, M., A. Fusco, M. Santoro, R. M. Melillo, M. T. Berlingieri, M. A. Pierotti, G. Della Porta, and G. Vecchio. 1989. PTC oncogene is a novel rearranged form of the ret oncogene and is frequently detected in vivo in human thyroid papillary carcinomas. $A n$ nales D'Endocrinologie. 129. (Abstr.)

25. Studer, H., H. J. Peter, and H. Gerber. 1989. Natural heterogeneity of thyroid cells: the basis for understanding thyroid function and nodular goiter growth. Endocrinol. Rev. 10:125-135.

26. Peter, H. J., H. Gerber, H. Studer, D. V. Becker, and M. E. Peterson. 1987. Autonomy of growth and of iodine metabolism in hyperthyroid feline goiters transplanted onto nude mice. J. Clin. Invest. 80:491-498.

27. Peter, H. J., H. Studer, and P. Groscurth. 1987. Autonomous growth, but not autonomous function, in embryonic human thyroids: A clue to understanding autonomous goiter growth? J. Clin. Endocrinol. Metab. 66:968-973.

28. Gerber, H., H. Studer, A. Conti, H. Engler, H. Kohler, and A. Haeberli. 1981. Reaccumulation of thyroglobulin and colloid in rat and mouse thyroid follicles during intense thyrotropin stimulation. A clue to the pathogenesis of colloid goiters. J. Clin. Invest. 68:13381347.

29. Namba, H., S. R. Rubin, and J. A. Fagin. 1990. Point mutations of ras oncogenes are an early event in thyroid tumorigenesis. Clin. Res. 38:99a. (Abstr.) 